\title{
Decisionmaking and Leadership in Crises and Beyond
}

\author{
TUIJA TAKALA and MATTI HÄYRY
}

Bioethics is about decisionmaking. It is also about leadership in the making and implementing of those decisions, as we have seen during the coronavirus disease 2019 (Covid-19) pandemic. ${ }^{12}$ This special section presents a collection of views on how we should proceed in the current crisis and beyond.

The collection opens with Joseph Fins' powerful firsthand perspective on do not resuscitate (DNR) orders during the worst days of the Covid-19 crisis in New York. With shortage of both personnel and equipment, unilateral DNR orders were issued without consulting the patient or her proxies. With the reported low survival rate after resuscitation and the high risk that incubation causes to healthcare professionals, especially when adequate personal protective equipment (PPEs) are not available, this practice was not without justification, but it should not be allowed to become the new normal. The acceptable practices of DNR orders need to be considered carefully, not only as a question of medical ethics, but also as a part of a wider framework of social justice. The fact that unilateral DNR orders disproportionally affect minorities should cause further concern.

In their contribution, Stephen Rainey and Alberto Giubilini study the legitimacy of restricting rights and freedoms during an emergency, such as the Covid-19 pandemic. By utilizing John Stuart Mill and Jürgen Habermas' arguments, they argue that in a state of an emergency, protecting lives and guaranteeing healthcare provision need to take priority and other, lesser, values can be temporarily suspended as long as it is done along the Principle of Least Restrictive Alternative and to protect the values of the society prior to the emergency. In their analysis, the extraordinary measures taken by the governments during an emergency find their ultimate justification in that those measures are put in place to make sure that a return to status quo ante is possible after the crisis is over.

Floris Tomasini studies the different shapes and forms that solidarity has taken in the time of Covid-19. Deviating from the overall conclusion of the previous paper, Tomasini argues that returning to the status quo after the pandemic is over is not desirable. Unlike Rainey and Giubilini, he does not look at the justification of the restrictive measures, but rather his analysis centers on the causes of the crisis. According to him, it is ultimately the business-as-usual anthropocentric solidarity that is to be blamed for the pandemic and therefore, after the crisis, we

Acknowledgments: Our thanks are due, for financial support, to the Academy of Finland (project Bioeconomy and Justice, SA 307467) and the Finnish Ministry of Agriculture and Forestry (projects The Role of Justice in Decisionmaking Concerning Bioeconomy and A Just Management Model for Systemic and Sustainable Shift Towards Bioeconomy). 
need to start embracing a more bio-centric notion of solidarity to avoid such pandemics in the future.

Jurgen De Wispelaere and Leticia Morales support the use of Emergency Basic Income (EBI) as a response to the Covid-19 pandemic and other similar crises in the future. They point out how unemployment, poverty, and economic insecurity are linked with poor health outcomes. Consequently, according to them, contrasting health against economic opportunity and security in a pandemic is mistaken. Dire economic situations go hand in hand with health problems, so what we really should be talking about, is health-health trade-offs. De Wispelaere and Morales argue that EBI would tackle the issue in an immediate and agile way, it would protect the vulnerable, and, if financed with a temporary progressive tax, it would also be solidaristic. They further assert that a Universal Basic Income (UBI) would allow us to be better prepared for similar crises in the future. Rainey and Giubilini argue in their contribution that the desire to build a system like the UBI can indeed be prompted by an existing crisis, but that the crisis cannot justifiably be the mechanism delivering that change.

Although a system like the EBI is set up to mitigate the effects of the pandemic, there have been a multitude of regulatory actions taken to curtail it. Most countries went to a lockdown mode for a period of time to stop the spread of the virus. In his contribution, David Shaw uses the United Kingdom, and especially Scotland, as an instance to study the letter and spirit of lockdown regulations and the degree to which they are respected. He analyses ethically four lockdown-related cases and concludes that for the general public to respect the rules, it is imperative that those who draft the guidelines obey them and respect them both in letter and in spirit. This is a question of leadership by example.

As a future measure to control the spread of the virus, many countries are in the process of setting up voluntary contact tracing smartphone applications. In India, the government-backed app, "Aarogya Setu" is already running and its use is mandatory in certain circumstances. In his article, Saurav Basu studies the benefits and harms of such an application. Although recognizing the challenges to privacy and data security, he maintains that these have been adequately addressed in "Aarogya Setu" and that the benefits of being able to trace potential carriers, and to identify and make predictions of hotspots, are too significant to dismiss. After careful analysis, he concludes that "Aarogya Setu" is a legitimate public health intervention.

In the direst cases, the pandemic overwhelms the healthcare system, and there simply is not enough space, equipment and/or staff to help those who under normal circumstances could be helped. Fins' contribution alerted us to the cases of unilateral DNR orders, whereas Joel Michael Raynolds, Laura Guidry-Grimes, and Katie Savin scrutinize the shortage of ventilators caused by excessive numbers of Covid-19 patients. The crisis has led to discussions about ventilator allocationand reallocation-during a crisis standard of care. In the State of New York, for instance, the National Guard was authorized to take control of excess community ventilators and reallocate those to overwhelmed hospitals in an attempt to maximize lives saved. Raynolds, Guidry-Grimes, and Savin concentrate their attention on personal ventilators, medical devices that many people with disabilities need to realize liveable pulmonary function in their everyday life. Through ethical analysis and case studies, they show that personal ventilators should be left out of 
reallocation pools as any other approach would be a direct assault on the personal and social integrity of the people to whose ventilators the allocation would apply.

The paper by Kelsey Gipe studies the concept of biofixture, and what it might entail morally, in more general terms. She does not discuss triages or crises standard of care situations; but, is more focused on end of life decisions and questions like: if a pacemaker is a biofixture, does turning it off count as active euthanasia rather than withdrawal of treatment? Her careful analysis has wider implications in terms of what kinds of medical devices would count as biofixtures and under what circumstances. As medical technologies advance and implantable devices develop, we are likely to see an increase in artificial therapies that become "part of the patient." In addition to giving guidance in end-of-life situations, her analysis could help us in future crises by giving us some guidance as to which medical devices could legitimately be pooled for reallocation.

Göran Hermerén discusses the specific case of migrants in need of heart transplants, but his analysis could well be applied to other healthcare needs of migrants and, even more widely, it touches upon the idea of international patients and their right to healthcare. The Covid-19 pandemic has made us painfully aware that diseases do not respect national borders and that to overcome global health problems, we need to work together. International co-operation requires global regulatory frameworks and ideally, shared ethical codes. However, even if these could be reached, the disparities in economic and technical development between the countries create additional problems.

In her contribution to this special section, Elizabeth Lanphier argues that the idea of self-ownership is not enough to guarantee a right to healthcare, or more specifically, to ensure reproductive justice. She further points out that selfownership is conceptually compromised because it is based on property rights, which "build upon and replicate historical injustices." Relying on self-ownership alone would, for instance, according to her, make public health measures that include positive duties and limits to personal rights obsolete. However, as the current pandemic has shown us, the countries that applied minimal public health interventions have been the least successful in reducing and controlling Covid-19 infections and death.

Public health is becoming more and more forward-looking. Even with Covid-19, after curtailing the first wave emergencies, public health officials are concentrating on forecasting and mitigating the future spread of the virus. Johann-Christian Põder's contribution focuses on predictive public health and studies whether, and to what degree, it would be acceptable and beneficial to stigmatize people for not knowing about their risks. According to his analysis, the right not to know should be the default policy in healthcare. Strong stigmatization does not work and produces counterproductive effects. He, however, wants to leave the door open for the use of slight stigma and shame, such as nudging and negative social marketing, as those can sometimes produce desired results.

Unlike the other contributions to this special section that address a practical ethical problem, the last three papers of the section start with a theory; the theory of liberal utilitarianism. It was first developed by Matti Häyry in his 1994 book, Liberal Utilitarianism and Applied Ethics ${ }^{3}$ and receives an updated defence in this special section. Häyry outlines the theory that he believes could provide a solid basis for moral and political choices in bioethics and elsewhere. Through historical and systematic comparative work, he shows how liberal utilitarianism could provide 


\section{Guest Editorial}

answers where other theories fall short. He further contends that better than any of the competing theories, liberal utilitarianism is capable of addressing some of the most pressing issues of the day, including environmental decay, the plight of nonhuman animals, and international aid.

Joona Räsänen agrees with Häyry's general defense of liberal utilitarianism, but argues that the theory needs to be more explicit about who belongs to our moral community. Räsänen thinks that Häyry's exclusion of "nonexistent beings who will never come into existence" does not adequately address certain reproductive decisions. Perhaps more crucially though, he argues that Häyry's theory needs further clarification when it comes to human animals at the "margins of life." If ability to suffer is morally relevant, then, for instance, the right to abortion (which Häyry seems to believe in) might be in jeopardy.

Henrik Rydenfelt's contribution brings us back to the topic of Covid-19. His careful scrutiny of liberal utilitarianism suggests that other theories of justice might not be quite as ill-equipped to deal with the pressing issues of today as Häyry seems to think. However, with the current pandemic, Rydenfelt postulates that the world seems to have taken a utilitarian turn. The ultimate good is largely defined in terms of wellbeing rather material and financial commodities. The sacrifices we thought unfeasible when faced with a more distant and less tangible threat of climate change were made in weeks when the reality of the pandemic hit. Maybe there is hope for making changes to combat the climate change as well. Then again, there are parochial elements, Rydenfelt argues, to the wellbeing that Covid-19 has brought to the limelight that might be quite different from what a utilitarian would like to see. Because of political mechanism, the responses to the virus have been largely on a national level, but we have also seen elements of rivalry between nations when it comes to essential equipment to control the virus and future vaccines, and relatively lame efforts to support the developing countries in their struggles with the virus. If the concern for wellbeing adopts a parochial guise, the motivation to fight climate change could be lost.

\section{Notes}

${ }^{1}$ Häyry, M. The COVID-19 pandemic: A month of bioethics in Finland. Cambridge Quarterly of Healthcare Ethics 2020;30(1):114-22. doi:10.1017/S0963180120000432.

${ }^{2}$ Häyry, M. The COVID-19 pandemic: Healthcare crisis leadership as ethics communication. Cambridge Quarterly of Healthcare Ethics 2020;30(1):42-50. doi:10.1017/S0963180120000444.

3 Häyry M. Liberal Utilitarianism and Applied Ethics. London/New York: Routledge; 1994. 


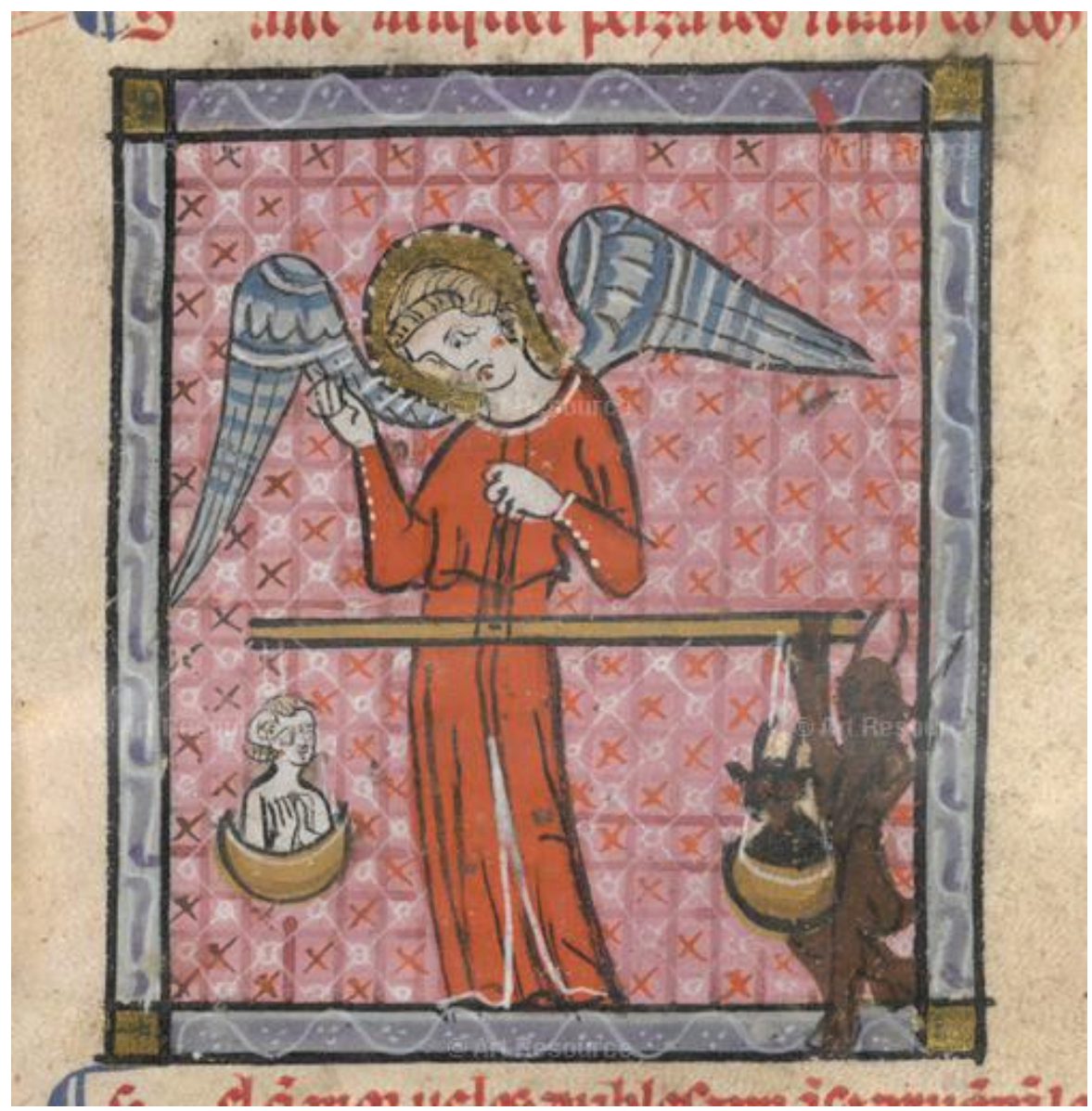

St Michael weighing souls, Image taken from Breviari d'Amors. Originally published/produced in Southern France; early 14th century. Location: British Library, London, Great Britain.

Photo Credit: @ British Library Board / Robana / Art Resource, New York, Reproduced by Permision. 